\section{IJ§ER}

ISSN: 2149-5939
International Journal of Social Sciences and Education Research

Online, http://dergipark.gov.tr/ijsser

Volume: 3(1), 2017

\title{
Çocukluk çağı travması ve benlik saygısı
}

\section{Childhood trauma and self-respect}

\begin{abstract}
Elif Güneri Yöyen ${ }^{1}$
Received Date: 01 / 09 / 2016

Accepted Date: 24 / 12 / 2016

$\ddot{O} z$

Bu çalışmanın amacı, çocukluk çağı travmaları ve benlik saygısı arasındaki ilişkinin, çocukluk çağı travma oranının ve cinsiyet dağılımının incelenmesidir. Araştırma verileri 2014-2015 eğitim öğretim yılında İstanbul Gelişim Üniversitesi İktisadi İdari Sosyal Bilimler Fakültesi 'nde öğrenim gören 530 ögrenciden elde edilmiştir. Araştırmada "Rosenberg Benlik Saygısı Ölçeği " ve "Çocukluk Çă̆ı Travmaları Ölçeği”" kullanılmış, veriler IBM SPSS 22.0 programıyla analiz edilmiştir. Araştırmanın sonucunda çocukluk çağı travmasının mevcut olmasının benlik saygısını düşük benlik saygısı lehine yükselttiği; ancak benlik saygısı düzeyinin belirleyicisi olarak çocukluk çağı travmalarının açıklayıcılık gücünün zayıf olduğu saptanmıştır. Diğer bulgular şu şekildedir: Çocukluk çağı travması alt boyutlarının tamamı (duygusal istismar, fiziksel istismar, fiziksel ihmal, duygusal ihmal ve cinsel istismar) benlik saygısını düşük benlik saygısı lehine yükseltmektedir. Erkek ögrencilerde çocukluk çağı travması ve alt boyut olarak fiziksel ihmal ve cinsel istismar, kız ögrencilere göre daha fazla oranda saptanmıştır. Bir diğer sonuç duygusal istismar, fiziksel istismar ve duygusal ihmal alt boyutlarının cinsiyete göre farklılı oluşturmamış olmasıdır.
\end{abstract}

Anahtar Sözcükler: Çocukluk çă̆ı travması, benlik sayglsı, istismar, ihmal, cinsiyet

\begin{abstract}
This study aims to examine the rate of childhood trauma, gender distribution and the relation between childhood trauma and self-respect. The research data was produced out of 530 university students at Istanbul Gelişim University, Faculty of Economics, Administrative and Social Sciences in the 2014-2015 academic year. In the research "Rosenberg Self-Respect Scale" and "Childhood Trauma Scale" were used and the data was analyzed by IBM SPSS 22.0. What was observed at the end of the research is as follows: The fact that childhood trauma exists decreases self-respect; as a determiner of self-respect level childhood trauma is a feeble factor to give reasons; all the sub-dimensions of childhood trauma (emotional abuse, physical abuse, physical neglect, emotional neglect and sexual abuse) decrease self-respect; childhood trauma and as subdimensions physical neglect and sexual abuse in male students are higher than in female students; emotional abuse, physical abuse,emotional neglect subdimensions don't differ when it comes to gender.
\end{abstract}

Keywords: Childhood trauma, self-respect, abuse, neglect, gender

\section{Giriş}

Bireyin ruhsal yapılanmasına yönelik en ağır şiddet türü olarak düşünülen çocukluk çağı travmalarının bireylerin psikolojik ve sosyal gelişimlerini derinden etkilediği ancak ülkemizde konuya ilişkin çalışmaların sayıca az olduğu; alınan psikolojik, sosyal, eğitsel ve hukuki önlemlerin yetersiz olduğu; bunun bir sebebinin de bu yaşantıya maruz kalan çocukların ve onların ailelerinin konu hakkında bildirim yapmaktan kaçınmaları olduğu bilinmektedir. Bu çalışmanın amacı ileri düzey eğitim kurumlarında bulunan bireylerin bu bildirimi yapmaktan kaçınmayacağı varsayımı

\footnotetext{
${ }^{1}$ Corresponding Author: Assist. Prof. Dr. İstanbul Gelişim University, İstanbul, TURKEY, eguneri@gelisim.edu.tr
} 
Güneri Yöyen, E. (2017). Çocukluk çağı travması ve benlik saygısı. International Journal of Social Sciences and Education Research, 3(1), 267-282.

ile geriye dönük bir tarama çalışması yaparak çocukluk çağı travmasının oranı, travmanın cinsiyet dağılımı ve benlik saygısını ne düzeyde etkilediğine yönelik verilere ulaşmaktır.

Çalışmanın gerek çocukluk çağı ve benlik saygısı arasındaki ilişkinin belirlenmesi ve bireylerin çocukluk çağı travmasına bağlı düşük benlik saygılarının yükseltilmesi konusunda tüm ruh sağlığ çalışanlarının ve sosyal bilimler alanında çalışanların dikkatini çekmek ve gerekse ülkemizde çocukluk çağı travmasının oranının belirlenmesinde ve bireysel, sosyal ve hukuki önlemlerin alınmasında katkı sağlamak adına önemli olduğu düşünülmektedir.

Araştırmanın problemleri şunlardır?

Çocukluk çağı travmaları ile benlik saygısı arasında bir ilişki var mıdır?

Çocukluk çağı travmaları alt boyutları ile benlik saygısı arasında bir ilişki var mıdır?

Çocukluk çağı travması ve alt boyutlarının oranı nedir?

Çocukluk çağı travması ve travma alt boyutlarının cinsiyete göre dağılımı nedir?

\section{Literatür}

Çocukluk çağı travması çocuklukta veya genç erişkinlikte yaşanan fiziksel istismar, duygusal istismar, cinsel istismar, fiziksel ihmal ve duygusal ihmal yaşantılarının genel bir ismidir ve literatürde sıklıkla istismar ve ihmal kavramları ile açıklanmaktadır. Buna göre 18 yaşın altındaki çocuklara karşı aktif olarak yapılan fiziksel, duygusal, zihinsel ve toplumsal gelişimlerini zedeleyici her tür davranışın istismar; onların beslenme, bakım, gözetim, eğitim gibi ihtiyaçlarının karş1lanmaması ise ihmal olarak kabul edilmektedir (Demirkap1, 2013: s.1-6)

Cinsel istismar; henüz cinsel gelişimini tamamlamamış bir çocuğun ya da ergenin, bir erişkin tarafından cinsel arzu ve gereksinimlerini karşılamak için güç kullanarak, tehdit ya da kandırma yolu ile kullanılması (Aktepe, 2009: s. 95-119); fiziksel istismar; çocuğu hırpalama, yaralama, dövme, yakma, tokat atma, yumruk atma, itip kakma, tekmeleme, vurma, sarsma, boğma, zehirleme, firlatma, kemer ya da kayışla vurma ya da çocuğa bir şekilde kasten fiziksel olarak zarar verme (Ekinci, 2010: s.625- 631); duygusal istismar; çocuğa bağırma, alaylı konuşma ve lakap takma, küfretme, küçük düşürme, reddetme, tehdit etme, saatlerce bir yerde kilitli tutma gibi eylemleri içeren ve çocuğun ihtiyacı olan ilgi, sevgi ve bakımın verilememesi ile karakterize çocuk ile bakım veren arasında normal hale gelmiş zarar verici tekrarlı bir etkileşim örüntüsü (Şenkal ve Işıkl1, 2013: s. 261-67); fiziksel ihmal; 18 yaşından küçük çocuk ya da gencin yetersiz besleme, giydirme, hijyen ya da bakım verme sonucunda zarara uğraması (Taner ve Gökler, 2004: s. 8286); duygusal ihmal; çocuğa duygusal ve bilişsel gelişimi için ihtiyaç duyduğu ilgi ve sevgi göstermemek ( Glaser, 2002: s. 697-714) olarak tanımlanmaktadır.

Bir toplumun kalkınabilmesi ve ilerleyebilmesi, o toplum içinde yetişen çocukların bedensel, sosyal ve ruhsal yönden sağlıklı gelişmesiyle mümkün olmaktadır. Ana baba ya da bakıcı gibi bir erişkin tarafından çocuğa yöneltilen, toplumsal kurallar ve profesyonel kişilerce uygunsuz ya da hasar verici olarak nitelendirilen, fiziksel, duygusal, zihinsel, cinsel gelişimlerini engelleyen, beden veya ruh sağlığına zarar veren, kaza sonucu olmayan durumlarla karşı karşıya bırakılması sonucu çocuğun gelişimini engelleyen veya kısıtlayan olayların tümü çocukluk çağı istismarı ve ihmali (Zeren ve ark., 2012: s. 536-541) ve bu sağliklı gelişimi engellemektedir.

Çocukluk dönemi istismar ve ihmal yaşantısı bireyin gelişim sürecinde istenmeyen sonuçlar doğurabileceği bilinmektedir ( Richards ve O'Keeffe, 2004:s. 338-352). Çocukluk çağı istismarı 
Güneri Yöyen, E. (2017). Childhood trauma and self-respect. International Journal of Social Sciences and Education Research, 3(1), 267-282.

ve ihmalinin bireyde psikopatoloji gelişiminde önemli olduğu (Etain ve ark., 2010:s. 376-383); dissosiyatif belirtiler (Evren ve Ögel, 2003 :s. 30-37); kendine fiziksel olarak zarar verme ve özkıyım davranışı ( Zoroğlu ve ark., 2001:s. 69-78); antisosyal kişilik bozukluğu (Algül ve ark., 2009: s. 278-285); özellikle duygudurum ve anksiyete bozuklukları başta olmak üzere diğer psikiyatrik hastalıklar (Örsel ve ark., 2011:s. 130-136); uyku bozuklukları, kabuslar, fobiler, bedensel yakınmalar, korku tepkisi, dikkat eksikliği ve hiperaktivite bozukluğu, ikincil enürezis, istismarın erken döneminde amnezi, aşırı fantezi kurma, trans benzeri durumlar, uyurgezerlik, yüksek oranda depresyon, travma sonrası stres bozukluğu, somatizasyon bozukluğu, hipokondriazis, yeme bozuklukları, cinsel işlev bozukluğu, borderline kişilik bozukluğu, konversiyon bozukluğu, gelişimsel bozukluklar, panik bozukluğu, suç işleme ve şiddet davranışında artış (Güleç,Topaloğlu, Ünsal ve Altıntaş, 2012: s. 112-137) ile ilişkili ve önemli bir faktör olduğu bilgisi yer almaktadir.

Benlik saygısı; kişinin kendini değerlendirmesi sonucunda ortaya çıkan, kendisini olduğundan aşağı ya da üstün görmeksizin kendinden memnun olma durumudur. Arkadaşlar ve aileden alınan sosyal destekle artan benlik saygısı öğrenilen bir fenomen ve yaşam boyu devam eden bir süreçtir ve benlik saygısının gelişmeye başladığı çocukluk döneminde istismar ve ihmal edilen çocukların benlik saygıları olumsuz etkilenebilmektedir. (Onat, Dinç, Günaydın ve Uğurlu, 2016: s. 9-15). Çocukluk çağ 1 travması, istismar ve ihmalinin psikiyatrik hastalıkların yanı sıra bireyin benlik saygısını önemli ölçüde etkilediği bilgisini rapor eden çalışma bulguları mevcuttur ( Pelcovitz ve ark., 1994: s.305-312; Özmert, 2006: s. 256-273; Tıraş̧1 ve Gören, 2007: s. 70-74; Eroğlu ve Türk, 2013: s. 1422-1439; Peled, 1998: s. 395-430; Joslyn ve Shivakumara, 2013: s. 438; Tyler, 2002: s. 567-589; Ovayolu, Uçan, Serindağ, 2007: s.4)

\section{Yöntem}

$\mathrm{Bu}$ çalışmada betimsel tarama yöntemi kullanılmıştır. Araştırmanın evrenini, 2014-2015 eğitim-öğretim yılında İstanbul Gelişim Üniversitesi İktisadi İdari Sosyal Bilimler Fakültesi’nde öğrenim gören öğrencileri oluşturmaktadır. Araştırmanın örneklemini ise evren kapsamında gönüllülük esasına göre araştırmaya katılan 1., 2., 3. ve 4. sınıflarda öğrenim gören toplam 530 katılımc1 oluşturmaktadır. Araştırmaya katılan öğrencilerin 303'ü (\%57,2) kadın, 227'si (\%42,8) erkektir.

Araştırma verileri Rosenberg Benlik Saygısı Ölçeği ve Çocukluk Çağı Travmaları Ölçeği kullanılarak elde edilmiştir. Rosenberg Benlik Saygısı Ölçeği: Rosenberg tarafından 1965 yılında geliştirilmiş olan ölçek toplam 63 soru ve 12 alt ölçekten oluşmaktadır. Çuhadaroğlu tarafından 1986 yılında Türkçeye uyarlama çalışması yapılmıştır. Ölçeğin geçerlilik oranı 0.71 , test -tekrar test güvenilirlik katsayısı 0.75 olarak belirtilmiştir (Çeçen, 2008). Bu araştırmada sadece benlik saygısı alt testi kullanılmıştır. Guttman ölçüm şekline göre düzenlenmiş testte, olumlu ve olumsuz yüklü maddeler ardışık olarak sıralanmıştır. Ölçeğin kendi içinde değerlendirme sistemine göre denekler 0 ile 6 arasında puan almaktadırlar. Sayısal ölçümlerle yapılan karşılaştırmalarda benlik sayg1s1, yüksek (0-1 puan), orta (2-4 puan) ve düşük (5-6 puan) olarak değerlendirilmektedir. Puanın yüksek olması benlik saygısının düşük, az olması ise benlik saygısının yüksek olduğunu göstermektedir (Balat ve Akman, 2004: s. 175-183).

Çocukluk Çağı Travmaları Ölçeği: Bernstein ve arkadaşları tarafından geliştirilen ölçeğin Türkçe uyarlama ve geçerlilik ve güvenilirlik çalışması Şar ve arkadaşları tarafından 2012'de yapılmıştır. Yirmi sekiz maddeden oluşan ölçek çocukluk çağ istismarıyla ilişkili olarak cinsel, fiziksel, duygusal istismar ve duygusal ve fiziksel ihmal olmak üzere beş alt boyutu kapsamakta 
Güneri Yöyen, E. (2017). Çocukluk çağı travması ve benlik saygısı. International Journal of Social Sciences and Education Research, 3(1), 267-282.

olup tüm maddeler 5'li likert tipinde değerlendirilmektedir. Bu ölçek ile çocukluk çağı cinsel, fiziksel, duygusal istismarı ve duygusal ve fiziksel ihmali konu alan beş alt puan ile bunların birleşiminden oluşan toplam puan elde edilmektedir. Ölçeğin iç tutarlılığını gösteren Cronbach alfa değeri Türkçe uyarlama ve geçerlilik ve güvenilirlik çalışmasında tüm katılımcılardan oluşan grup için $(\mathrm{N}=123)$ 0,93 olarak bulunurken, Guttman yarım test katsayısı ise 0,97 olmuştur. Ölçeğin toplam puanının 2 hafta ara ile klinik olan ve olmayan katılımcılar üzerinde yapılan test tekrar test korelasyon katsayısı ( $<<0,001, \mathrm{~N}=48$ ) bulunmuştur (Şenkal ve Işıklı, 2015: s. 261267)

Tarama modelindeki bu araştırmada, öğrencilerin çocukluk çağı travma toplam puanları ortalamalarının cinsiyet değişkenine göre anlamlı bir farklılık gösterip göstermediğini belirlemek amacıyla t-testi; çocukluk çağı travma toplam puanı ile benlik saygısı arasındaki ilişkiyi belirlemek üzere korelasyon analizi; çocukluk çağı travmaları ile benlik saygısı arasındaki ilişki belirlemek üzere regresyon analizi; benlik saygısı açısından çocukluk çağı travması olan ve olmayan öğrencilerin karşılaştırılmasında ki-kare testi; dağılım ve tanımsal bulgular için frekans ve aritmetik ortalama kullanılmıştır. Araştırmadan elde edilen verilerin istatistiksel çözümlemeleri IBM SPSS 22.0 programı kullanılarak yapılmış ve araştırmada anlamlılık düzeyi [ $\mathrm{p} \leq .05]$ olarak kabul edilmiştir.

\section{Bulgular}

Tablo 1. Katılımcıların cinsiyet dağılımı

\begin{tabular}{|l|l|c|c|}
\hline & & Frekans(n) & Yüzde (\%) \\
\hline \multirow{3}{*}{ Cinsiyet } & Kadın & 303 & 57,2 \\
\cline { 2 - 4 } & Erkek & 227 & 42,8 \\
\cline { 2 - 4 } & Toplam & 530 & 100,0 \\
\hline
\end{tabular}

Araştırmaya katılanların 303'ü $(\% 57,2)$ kadın, 227'si $(\% 42,8)$ erkektir.

Tablo 2. Çocukluk çağı travma tanımsal bulguları

\begin{tabular}{|l|l|l|l|l|l|}
\hline & $\mathrm{n}$ & Ort & Ss & Min. & Max. \\
\hline Çocukluk Çağı Travma Toplam & 530 & 34,860 & 9,222 & 25 & 82 \\
\hline Duygusal İstismar & 530 & 6,580 & 2,445 & 5 & 20 \\
\hline Fiziksel İstismar & 530 & 5,420 & 1,470 & 5 & 19 \\
\hline Fiziksel İhmal & 530 & 6,800 & 2,290 & 5 & 17 \\
\hline Duygusal İhmal & 530 & 8,510 & 3,790 & 5 & 24 \\
\hline Cinsel İstismar & 530 & 6,380 & 3,601 & 5 & 25 \\
\hline
\end{tabular}

Katılımcıların "çocukluk çağı travma toplam" düzeyi $(34,860 \pm 9,222)$; "duygusal istismar" düzeyi (6,580 $\pm 2,445)$; "fiziksel istismar" düzeyi (5,420 $\pm 1,470)$; "fiziksel ihmal" düzeyi $(6,800$ $\pm 2,290)$; "duygusal ihmal” düzeyi ( $8,510 \pm 3,790)$; "cinsel istismar" düzeyi $(6,380 \pm 3,601)$ olarak hesaplanmıştır. 
Güneri Yöyen, E. (2017). Childhood trauma and self-respect. International Journal of Social Sciences and Education Research, 3(1), 267-282.

Tablo 3. Çocukluk çağı travma bulguları

\begin{tabular}{|c|l|c|c|}
\hline & & Frekans(n) & Yüzde (\%) \\
\hline \multirow{4}{*}{ Çocukluk Çağı } & Travma Yok & 365 & 68,9 \\
\cline { 2 - 4 } & Travma Var & 165 & 31,1 \\
\cline { 2 - 4 } & Toplam & 530 & 100,0 \\
\hline \multirow{4}{*}{ Duygusal İstismar } & Duygusal İstismar Yok & 390 & 73,6 \\
\cline { 2 - 4 } & Duygusal İstismar Var & 140 & 26,4 \\
\cline { 2 - 4 } & Toplam & 530 & 100,0 \\
\hline \multirow{3}{*}{ Fiziksel İhmal } & Fiziksel İstismar Yok & 464 & 87,5 \\
\cline { 2 - 4 } & Fiziksel İstismar Var & 66 & 12,5 \\
\cline { 2 - 4 } & Toplam & 530 & 100,0 \\
\hline \multirow{3}{*}{ Duygusal İhmal } & Fiziksel İhmal Yok & 369 & 69,6 \\
\cline { 2 - 4 } & Fiziksel İhmal Var & 161 & 30,4 \\
\cline { 2 - 4 } & Toplam & 530 & 100,0 \\
\cline { 2 - 4 } & Duygusal İhmal Yok & 447 & 84,3 \\
\cline { 2 - 4 } & Duygusal İhmal Var & 83 & 15,7 \\
\hline \multirow{3}{*}{ Cinsel İstismar } & Toplam & 530 & 100,0 \\
\cline { 2 - 4 } & Cinsel İstismar Yok & 434 & 81,9 \\
\cline { 2 - 4 } & Cinsel İstismar Var & 96 & 18,1 \\
\cline { 2 - 4 } & Toplam & 530 & 100,0 \\
\hline
\end{tabular}

Öğrencilerin 365'inde $(\% 68,9)$ travma saptanmamıştır, 165'inde ise $(\% 31,1)$ travma saptanmıştır. Öğrencilerin 390'unda $(\% 73,6)$ duygusal istismar mevcut değil, 140'ında $(\% 26,4)$ duygusal istismar mevcuttur. Öğrencilerin 464'ünde $(\% 87,5)$ fiziksel istismar mevcut değil, 66'sinda $(\% 12,5)$ fiziksel istismar mevcuttur. Öğrencilerin 369'unda (\%69,6) fiziksel ihmal saptanmazken, 161'inde $(\% 30,4)$ fiziksel ihmal saptanmıştır. Öğrencilerin 447 'sinde $(\% 84,3)$ duygusal ihmal mevcut değil, 83'ünde (\%15,7) duygusal ihmal mevcuttur. Son olarak öğrencilerin 434'ünde $(\% 81,9)$ cinsel istismar saptanmamıştır, 96 'sında $(\% 18,1)$ cinsel istismar saptanmıştır.

Tablo 4. Çocukluk çağı travması ile cinsiyet ilişkisi

\begin{tabular}{|l|c|c|c|c|c|c|}
\hline \multirow{2}{*}{} & \multicolumn{2}{|c|}{$\begin{array}{c}\text { Kadın } \\
(\mathrm{n}=303)\end{array}$} & \multicolumn{2}{c|}{$\begin{array}{c}\text { Erkek } \\
(\mathrm{n}=227)\end{array}$} & \multirow{2}{*}{$\mathrm{t}$} & \multirow{2}{*}{$\mathrm{p}$} \\
\cline { 2 - 5 } & Ort & $\mathrm{Ss}$ & Ort & Ss & & \\
\hline Çocukluk Çağı Travma Toplam & 33,780 & 8,315 & 36,300 & 10,151 & $-3,144$ & 0,002 \\
\hline Duygusal İstismar & 6,530 & 2,360 & 6,640 & 2,559 & $-0,500$ & 0,617 \\
\hline Fiziksel İstismar & 5,320 & 1,193 & 5,560 & 1,768 & $-1,851$ & 0,080 \\
\hline Fiziksel İhmal & 6,460 & 2,074 & 7,260 & 2,480 & $-4,083$ & 0,000 \\
\hline Duygusal İhmal & 8,410 & 3,634 & 8,640 & 3,992 & $-0,703$ & 0,482 \\
\hline Cinsel İstismar & 5,920 & 3,060 & 6,980 & 4,146 & $-3,392$ & 0,001 \\
\hline
\end{tabular}

Araştırmaya katılan öğrencilerin çocukluk çağı travma toplam puanları ortalamalarının cinsiyet değişkenine göre anlamlı bir farklılık gösterip göstermediğini belirlemek amacıyla yapılan ttesti sonucunda grup ortalamaları arasındaki fark istatistiksel açıdan anlamlı bulunmuştur $(\mathrm{t}=$ $3,144 ; \mathrm{p}=0,002<0,05)$. Erkeklerin çocukluk çağı travma toplam puanları $(\mathrm{x}=36,300)$, kadınların çocukluk çağı travma toplam puanlarından $(x=33,780)$ yüksek bulunmuştur. Fiziksel ihmal puanları cinsiyet değişkenine göre anlamlı bulunmuştur $(t=-4,083 ; p=0,000<0,05)$. Erkeklerin fiziksel ihmal puanları $(x=7,260)$, kadınların fiziksel ihmal puanlarından $(x=6,460)$ yüksek bulunmuştur. 
Güneri Yöyen, E. (2017). Çocukluk çağı travması ve benlik saygısı. International Journal of Social Sciences and Education Research, 3(1), 267-282.

Cinsel istismar puanları cinsiyet değişkenine göre anlamlı bulunmuştur ( $\mathrm{t}=-3,392 ; \mathrm{p}=0,001<0,05)$. Erkeklerin cinsel istismar puanları $(x=6,980)$, kadınların cinsel istismar puanlarından $(x=5,920)$ yüksek bulunmuştur.

Duygusal istismar $(\mathrm{t}=-0,500 ; \mathrm{p}=0,617>0,05)$; fiziksel istismar $(\mathrm{t}=-1,851 ; \mathrm{p}=0,080>0,05)$; duygusal ihmal puanlarında $(t=-0,703 ; p=0,482>0,05)$ ise cinsiyet değişkenine göre anlamlı bir farklilık saptanmamıştır.

Tablo 5. Çocukluk çağı travması ile benlik saygısı ilişkisine dair korelasyon analizi

\begin{tabular}{|l|c|c|c|c|c|c|c|}
\hline & & $\begin{array}{c}\text { Çocukluk çağ1 } \\
\text { travma toplam }\end{array}$ & $\begin{array}{c}\text { Duygusal } \\
\text { istismar }\end{array}$ & $\begin{array}{c}\text { Fiziksel } \\
\text { istismar }\end{array}$ & $\begin{array}{c}\text { Fiziksel } \\
\text { ihmal }\end{array}$ & $\begin{array}{c}\text { Duygusal } \\
\text { ihmal }\end{array}$ & $\begin{array}{c}\text { Cinsel } \\
\text { istismar }\end{array}$ \\
\hline \multirow{2}{*}{$\begin{array}{l}\text { Benlik Say- } \\
\text { gis1 }\end{array}$} & $\mathrm{r}$ & 0,239 & 0,261 & 0,243 & 0,184 & 0,193 & 0,051 \\
\cline { 2 - 8 } & $\mathrm{p}$ & 0,000 & 0,000 & 0,000 & 0,000 & 0,000 & 0,239 \\
\cline { 2 - 8 } & $\mathrm{N}$ & 530 & 530 & 530 & 530 & 530 & 530 \\
\hline
\end{tabular}

Çocukluk çağı travma toplam puanı ile benlik saygısı arasındaki ilişkiyi belirlemek üzere yapılan korelasyon analizi sonucunda, puanlar arasında $\% 23,9$ pozitif yönde anlamlı ilişki saptanmıştır $(r=0,239 ; p=0,000<0,05)$. Buna göre çocukluk çağı travma toplam puanı arttıkça benlik saygisı puanı da artmaktadır.

Tablo 6. Çocukluk çağı travmalarının benlik saygısına etkisine ilişkin Regresyon Analizi

\begin{tabular}{|c|c|c|c|c|c|c|c|}
\hline $\begin{array}{c}\text { Bağımlı Değiş- } \\
\text { ken }\end{array}$ & Bağımsız Değişken & ß & $\mathrm{t}$ & $\mathrm{p}$ & $\mathrm{F}$ & $\begin{array}{l}\text { Model } \\
\text { (p) }\end{array}$ & $\mathrm{R}^{2}$ \\
\hline \multirow{6}{*}{ Benlik Sayg1sı } & Sabit & 0,271 & 2,181 & 0,030 & \multirow{6}{*}{11,470} & \multirow{6}{*}{0,000} & \multirow{6}{*}{0,090} \\
\hline & Duygusal İstismar & 0,054 & 3,334 & 0,001 & & & \\
\hline & Fiziksel İstismar & 0,059 & 2,601 & 0,010 & & & \\
\hline & Fiziksel İhmal & 0,020 & 1,371 & 0,171 & & & \\
\hline & Duygusal İhmal & 0,009 & 0,901 & 0,368 & & & \\
\hline & Cinsel İstismar & $-0,016$ & $-1,757$ & 0,079 & & & \\
\hline
\end{tabular}

Çocukluk çağı travmaları ile benlik saygısı arasındaki ilişki belirlemek üzere yapılan regresyon analizi istatistiksel olarak anlamlı bulunmuştur $(\mathrm{F}=11,470 ; \mathrm{p}=0,000<0.05)$. Benlik saygıs1 düzeyinin belirleyicisi olarak çocukluk çağı travmaları değişkenleri ile ilişkisinin (açıklayıcılık gücünün) zayıf olduğu görülmüştür $\left(\mathrm{R}^{2}=0,090\right)$. Duygusal istismar düzeyi benlik saygısı düzeyini $(\beta=0,054)$, fiziksel istismar benlik saygısı düzeyini $(\beta=0,059)$ oranında artırmaktadır.

Fiziksel ihmal ( $\mathrm{p}=0.171>0.05)$; duygusal ihmal $(\mathrm{p}=0.368>0.05)$; cinsel istismar $(\mathrm{p}=0.079>0.05)$ puanlarının ise benlik saygısı düzeyini etkileme gücünün istatistiki olarak bir anlamlılık oluşturmadığı saptanmıştır.

Tablo 7. Çocukluk çağı travması ile benlik saygısı ilişkisine ilişkin Kikare Analizi

\begin{tabular}{|c|c|c|c|c|c|c|}
\hline & \multicolumn{2}{|c|}{ Çocukluk Çağı Travması Yok } & \multicolumn{2}{|c|}{ Çocukluk Çağı Travması Var } & \multirow[b]{2}{*}{ p } \\
\hline & & $\mathrm{n}$ & $\%$ & $\mathrm{n}$ & $\%$ & \\
\hline \multirow{2}{*}{ Benlik Saygısı } & Orta & 19 & $\% 5,2$ & 25 & $\% 15,2$ & \multirow{2}{*}{$\begin{aligned} X^{2} & =14,766 \\
p & =0,000\end{aligned}$} \\
\hline & Yüksek & 346 & $\% 94,8$ & 140 & $\% 84,8$ & \\
\hline
\end{tabular}

Benlik saygısı açısından çocukluk çağı travması olan ve olmayanlar arasında anlamlı fark bulunmuştur $\left(X^{2}=14,766 ; p=0,000<0.05\right)$. Çocukluk çağı travması bulunmayanların 19 'unun $(\% 5,2)$ 
Güneri Yöyen, E. (2017). Childhood trauma and self-respect. International Journal of Social Sciences and Education Research, 3(1), 267-282.

orta, 346'sının $(\% 94,8)$ yüksek; çocukluk çağı travması bulunanların 25'i $(\% 15,2)$ orta, 140'ının $(\% 84,8)$ yüksek benlik düzeyinin bulunduğu saptanmıştır.

Tablo 8. Duygusal istismar ile benlik saygısı ilişkisine ilişkin Kikare Analizi

\begin{tabular}{|c|l|c|c|c|c|c|}
\hline \multicolumn{2}{|c|}{} & \multicolumn{2}{|c|}{ Duygusal İstismar Yok } & \multicolumn{2}{|c|}{ Duygusal İstismar Var } & \multirow{2}{*}{$\mathrm{p}$} \\
\cline { 3 - 6 } \multicolumn{2}{|c|}{} & $\mathrm{n}$ & $\%$ & $\mathrm{n}$ & $\%$ & \\
\hline \multirow{2}{*}{ Benlik Sayg1S1 } & Orta & 25 & $\% 6,4$ & 19 & $\% 13,6$ & $\mathrm{X}^{2}=6,940$ \\
& Yüksek & 365 & $\% 93,6$ & 121 & $\% 86,4$ & $\mathrm{p}=0,009$ \\
\hline
\end{tabular}

Benlik saygısı açısından duygusal istismar yaşayanlar ve yaşamayanlar arasında anlamlı fark bulunmuştur $\left(\mathrm{X}^{2}=6,940 ; \mathrm{p}=0,009<0.05\right)$. Buna göre duygusal istismar yaşamamış olanların $25^{\prime} \mathrm{i}$ $(\% 6,4)$ orta, 365'i $(\% 93,6)$ yüksek; duygusal istismar yaşamış olanların 19'unun $(\% 13,6)$ orta, 121 'i $(\% 86,4)$ yüksek olduğu görülmektedir.

Tablo 9. Fiziksel istismar açısından benlik saygısı ilişkisine ilişkin Kikare Analizi

\begin{tabular}{|c|c|c|c|c|c|c|}
\hline & & \multicolumn{2}{|c|}{ Fiziksel İstismar Yok } & \multicolumn{2}{|c|}{ Fiziksel İstismar Var } & \multirow{2}{*}{$\mathrm{p}$} \\
\hline & & $\mathrm{n}$ & $\%$ & $\mathrm{n}$ & $\%$ & \\
\hline \multirow{2}{*}{ Benlik Saygısı } & Orta & 32 & $\% 6,9$ & 12 & $\% 18,2$ & \multirow{2}{*}{$\begin{array}{l}X^{2}=9,667 \\
p=0,004\end{array}$} \\
\hline & Yüksek & 432 & $\% 93,1$ & 54 & $\% 81,8$ & \\
\hline
\end{tabular}

Benlik saygısı açısından fiziksel istismar yaşayanlar ve yaşamayanlar arasında anlamlı fark bulunmuştur $\left(X^{2}=9,667 ; p=0,004<0.05\right)$. Fiziksel istismar yaşamamış olanların 32'si $(\% 6,9)$ orta, 432 'si $(\% 93,1)$ yüksek; fiziksel istismar yaşamış olanların 12'si $(\% 18,2)$ orta, 54 'ünün $(\% 81,8)$ yüksek olduğu görülmektedir.

Tablo 10. Fiziksel ihmal açısından benlik saygısı ilişkisine ilişkin Kikare Analizi

\begin{tabular}{|c|c|c|c|c|c|c|}
\hline & & \multicolumn{2}{|c|}{ Fiziksel İhmal Yok } & \multicolumn{2}{|c|}{ Fiziksel İhmal Var } & \multirow{2}{*}{$\mathrm{p}$} \\
\hline & & $\mathrm{n}$ & $\%$ & $\mathrm{n}$ & $\%$ & \\
\hline \multirow[b]{2}{*}{ Benlik Saygısı } & Orta & 25 & $\% 6,8$ & 19 & $\% 11,8$ & \multirow{2}{*}{$\begin{array}{c}\mathrm{X}^{2}=3,72 \\
0 \\
\mathrm{p}=0,042\end{array}$} \\
\hline & Yüksek & 344 & $\% 93,2$ & 142 & $\% 88,2$ & \\
\hline
\end{tabular}

Benlik saygısı açısından fiziksel ihmal yaşayanlar ve yaşamayanlar arasında anlamlı fark bulunmuştur $\left(\mathrm{X}^{2}=3,720 ; \mathrm{p}=0,042<0.05\right)$. Fiziksel ihmal yaşamamış olanların $25^{\prime} \mathrm{i}(\% 6,8)$ orta, 344'ünün $(\% 93,2)$ yüksek; fiziksel ihmal yaşamış olanların 19'unun $(\% 11,8)$ orta, 142 'si $(\% 88,2)$ yüksek olduğu görülmektedir.

Tablo 11. Duygusal ihmal açısından benlik saygısı ilişsisine ilişkin Kikare Analizi

\begin{tabular}{|c|c|c|c|c|c|c|}
\hline & \multicolumn{2}{|c|}{ Duygusal İhmal Yok } & \multicolumn{2}{|c|}{ Duygusal İhmal Var } & \multirow{2}{*}{$\mathrm{p}$} \\
\hline & & $\mathrm{n}$ & $\%$ & $\mathrm{n}$ & $\%$ & \\
\hline \multirow{2}{*}{ Benlik Saygısı } & Orta & 32 & $\% 7,2$ & 12 & $\% 14,5$ & \multirow{2}{*}{$\begin{array}{c}X^{2}=4,899 \\
p=0,028\end{array}$} \\
\hline & Yüksek & 415 & $\% 92,8$ & 71 & $\% 85,5$ & \\
\hline
\end{tabular}

Benlik saygısı açısından duygusal ihmal yaşayanlar ve yaşamayanlar arasında anlamlı fark bulunmuştur $\left(\mathrm{X}^{2}=4,899 ; \mathrm{p}=0,028<0.05\right)$. Duygusal ihmal yaşamamış olanların 32 'si $(\% 7,2)$ orta, 415 'i $(\% 92,8)$ yüksek; duygusal ihmal yaşamış olanların 12 'si $(\% 14,5)$ orta, 71 'i $(\% 85,5)$ yüksek olduğu görülmektedir. 
Güneri Yöyen, E. (2017). Çocukluk çağı travması ve benlik saygısı. International Journal of Social Sciences and Education Research, 3(1), 267-282.

Tablo 12. Cinsel istismar açısından benlik saygısı ilişkisine ilişkin Kikare Analizi

\begin{tabular}{|c|l|c|c|c|c|c|}
\hline \multicolumn{2}{|c|}{} & \multicolumn{2}{|c|}{ Cinsel İstismar Yok } & \multicolumn{2}{|c|}{ Cinsel İstismar Var } & \multirow{2}{*}{$\mathrm{p}$} \\
\cline { 2 - 6 } \multicolumn{2}{|c|}{} & $\mathbf{n}$ & $\mathbf{\%}$ & $\mathbf{n}$ & $\mathbf{\%}$ & \\
\hline \multirow{2}{*}{ Benlik Sayg1S1 } & Orta & 35 & $\% 8,1$ & 9 & $\% 9,4$ & $\mathrm{X}^{2}=0,177$ \\
\cline { 2 - 6 } & Yüksek & 399 & $\% 91,9$ & 87 & $\% 90,6$ & $\mathrm{p}=0,401$ \\
\hline
\end{tabular}

Benlik saygısı açısından cinsel istismar yaşayanlar ve yaşamayanlar arasında anlamlı fark bulunmamıştır $\left(\mathrm{X}^{2}=0,177 ; \mathrm{p}=0,401>0.05\right)$. Cinsel istismar yaşamamış olanların $35^{\prime} \mathrm{i}(\% 8,1)$ orta, 399 'unun $(\% 91,9)$ yüksek; cinsel istismar yaşamış olanların 9'unun $(\% 9,4)$ orta, 87'si $(\% 90,6)$ yüksek olduğu görülmektedir.

\section{Tartıșma}

Araştırmada katılımcıların \%31,1'inde çocukluk çağı travması; \%26,4'ünde duygusal istismar; \%12,5'inde fiziksel istismar; \%30,4'ünde fiziksel ihmal; \%15,7'sinde duygusal ihmal ve $\% 18,1$ 'inde cinsel istismar saptanmıştır. Alan yazını incelendiğinde çocukluk çağı travmasının toplumda görülme sıklığına dair farklı bilgiler yer almaktadır. Dünyada çocuk istismarı oranı kız çocuklarında $\% 52$ ve erkek çocuklarında \%48, Türkiye'de çocukların istismara maruz kalma oranı \%33 oranında saptanmış bulunduğu belirtilmektedir (Tirali, Oğuz ve Soydan, 2014: s. 154157). Bu araştırmada çocukluk çağı travma oranı \% 31.1 olarak belirlenmiştir ve Tirali’nin araştırma sonucunda yakın bir değer elde edilmiştir. Ancak UNICEF'in "Çocuk İstismarı ve Aile İçi Şiddet” araştırması (2010) Türkiye' de yaşayan 7-18 yaşlar arasındaki çocukların \%56'sının fiziksel istismara, \%49'unun duygusal istismara ve \%10'unun cinsel istismar mağduru olduğunu göstermektedir (Akbaş, 2014: s. 75-96). Başbakanlık Aile Araştırma Kurumunun Türkiye genelinde yaptığ 1 çalışmaya göre çocukların \%45'inin istismara uğradığı belirtilmiştir. (Güler, Uzun, Boztaş ve Aydoğan, 2002: s. 128-134). Zoroğlu tarafından 839 lise öğrencisi ile yapılan bir çalışmada duygusal ihmal \%16.5, duygusal istismar \%15.8, fiziksel istismar \%13.5 ve cinsel istismar ve \%10.7 olarak rapor edilmiştir (Zoroğlu ve ark., 2001: s. 69-78). 944 üniversite öğrencisi ile yap1lan bir başka çalışmada çocukluk dönemi istismarı \%17, cinsel istismar \%8.9, fiziksel istismar \%4.2 ve duygusal istismar \%8.6 olarak bildirilmiştir (Demirkapı, 2013: s.3). Bu farklılıkların örneklem grubu, kültürel ve sosyal yapı farklılıkları, araştırmada kullanılan ölçeklerin farklılığ sebepleri ile kaynaklandığı düşünülmektedir. Araştırmada çocukluk çağı travmalarının ilk sırasında duygusal istismar geldiği ve bunu fiziksel istismar, fiziksel ihmal, duygusal ihmal ve cinsel istismarın izlediği görülmektedir. Bulgu literatür ile uyumludur. Türkiye'de çocuk istismarı konusunda yapılan araştırmalarda, yüzde 78 gibi yüksek bir oran ile duygusal istismarın ilk sırada olduğu görülmektedir. Bunu sırası ile fiziksel istismar ve cinsel istismar izlemektedir (Turhan, Sangün ve İnand1, 2006: s.153)

Araştırmada ikinci bulgu çocukluk çağı travması ve travmanın bazı alt tiplerinin cinsiyete göre değişkenlik gösterdiğidir. Yapılan t-testi sonucunda grup ortalamaları cinsiyet açısından anlamlı farklılık göstermiştir $(\mathrm{t}=-3,144 ; \mathrm{p}=0,002<0,05)$. Erkeklerin çocukluk çağ 1 travma toplam puanları $(x=36,300)$, kadınların çocukluk çağı travma toplam puanlarından $(x=33,780)$ yüksek bulunmuştur. Çocukluk çağ oranında ve cinsel istismar puanları $(\mathrm{t}=-3,392 ; \mathrm{p}=0,001<0,05)$ oranında erkek öğrenciler lehine anlamlı bulunmuştur. Duygusal istismar $(\mathrm{t}=-0,500 ; \mathrm{p}=0,617>0,05)$; fiziksel istismar $(\mathrm{t}=-1,851$; $\mathrm{p}=0,080>0,05)$; duygusal ihmal puanlarında $(\mathrm{t}=-0,703 ; \mathrm{p}=0,482>0,05)$ ise cinsiyet değişkenine göre anlamlı bir farklılık saptanmamıştır. 
Güneri Yöyen, E. (2017). Childhood trauma and self-respect. International Journal of Social Sciences and

Education Research, 3(1), 267-282.

Araştırmada fiziksel ihmal ve cinsel istismarın erkeklerde kızlara göre daha fazla görüldüğü bilgisi literatür ile uyumludur. Ulusal veriler incelendiğinde çocukluk çağı travmalarını duygusal istismar ve ihmal, fiziksel istismar ve ihmal ve cinsel istismar olmak üzere üç boyutta değerlendiren çocukluk çağı örselenme ölçeği ile yapılan çalışmalarda ihmal ve istismarın erkeklerde kızlara göre daha fazla görüldüğü bilgisi yer almaktadır (Zeren ve ark., 2012: s. 536-541; Aslan ve Alparslan, 1999: s. 275-85; Özen, Antar ve Özkan, 2004: s. 316-9). Eroğlu ve Türk'ün 450 ergen ile yaptığı bir çalışmada cinsel istismarın erkeklerde kızlara göre daha yüksek olduğu bilgisi verilmiştir. (Eroğlu ve Türk, 2013: s. 1422-1439) Çocukluk çağı örselenme yaşantılarının ergenlerdeki flört kaygısının yordayıcısı olup olmadığının incelenmesi amacıyla 297 üniversite öğrencisi ile yapılan bir başka çalışmada da erkek öğrencilerde cinsel istismarın kız öğrencilerden daha fazla görüldüğü belirtilmiştir (Kalkan ve Özbek, 2011: s. 35-44). Üniversite öğrencilerinde çocukluk istismar ve ihmalinin sıklığı üzerine yapılan ve 150 üniversite öğrencisi ile yürütülen bir başka çalışmada duygusal, fiziksel ve cinsel istismar ve ihmal puanları erkek öğrencilerde kız öğrencilerine göre daha yüksek olarak tespit edilmiştir (Zeren ve ark., 2012:s. 536-541).

Araştırmada üçüncü bulgu çocukluk çağı travması yaşamış olmanın benlik saygısını düşürdüğü yönündedir. Çocukluk çağı travma toplam puanı ile benlik saygısı arasındaki ilişkiyi belirlemek üzere yapılan korelasyon analizi sonucunda, puanlar arasında $\% 23,9$ pozitif yönde anlamlı ilişki bulunmuştur $(r=0,239 ; \mathrm{p}=0,000<0,05)$. Buna göre çocukluk çağ 1 travma toplam puanı arttıkça benlik saygısı puanının da arttığı tespit edilmiştir. Çocukluk çağı travmaları ile benlik saygısı arasındaki ilişkinin gücünü belirlemek üzere yapılan regresyon analizi istatistiksel olarak anlamlı bulunmuştur $(\mathrm{F}=11,470 ; \mathrm{p}=0,000<0.05)$. Benlik saygısı düzeyinin belirleyicisi olarak çocukluk çağı travmaları değişkenleri ile zayıf bir ilişkinin olduğu görülmüştür $\left(\mathrm{R}^{2}=0,090\right)$. Buna göre duygusal istismar düzeyi benlik saygısı düzeyini $(\beta=0,054)$, fiziksel istismar benlik saygısı düzeyini $(\beta=0,059)$ oranında artırmaktadır.

Bulgu literatür ile uyumludur. Çocukluk dönemi istismar ve ihmalinin düşük benlik saygısı geliştirmede bir faktör olduğu bildirilmektedir (Özmert, 2006: s. 256-273; Tıraşçı ve Gören, 2007:s. 70-74). Yakın zamanlı bir ulusal çalışmada ergenlerde çocukluk örselenme yaşantıları ve öfke ifade biçimleri ile benlik saygısı ve yaşam doyumu arasındaki ilişkiler incelenmiş ve fiziksel, duygusal ve cinsel istismar yaşantısı geçiren ergenlerin geçirmeyenlere göre benlik saygısının düşük olduğunu saptanmıştır (Eroğlu ve Türk, 2013:s. 1422-1439). Çocukluk dönemi travmasının benlik saygısını düşürdüğ̈ yönündeki bulgulara ek olarak çocukların anne babaları tarafından istismar edilmelerinin değerlendirildiği bir çalışmada, babalarından ziyade anneleri tarafından istismar edildiklerinde özgüvenlerinin daha düşük olduğunu bildirilmiştir ( Peled, 1998: s.395-430)

Araştırmada son bulgusu çocukluk çağı travması olan öğrenciler ile travması olmayan öğrencilerin benlik saygılarının karşılaştırılması ile elde edilmiş ve çocukluk çağı travması olan ve olmayanlar arasında benlik saygisı açısından anlamlı fark bulunmuştur ( $X^{2}=14,766$; $\mathrm{p}=0,000<0.05)$. Çocukluk çağı travması bulunmayanların 19'unun $(\% 5,2)$ orta, 346'sının $(\% 94,8)$ yüksek; çocukluk çağı travması bulunanların $25^{\prime}$ i $(\% 15,2)$ orta, 140 'ının $(\% 84,8)$ yüksek benlik düzeyinin bulunduğu saptanmıştır. Çocukluk çağı travması alt tiplerinin benlik saygısına olan etkisi çocukluk çağı travması olan ve olmayan grubun karşılaştırılmasında duygusal istismar yaşayanlar ve yaşamayanlar arasında benlik saygısı açısından $\left(X^{2}=6,940 ; p=0,009<0.05\right)$; fiziksel istismar yaşayanlar ve yaşamayanlar arasında $\left(X^{2}=9,667 ; p=0,004<0.05\right)$; fiziksel ihmal yaşayanlar ve yaşamayanlar arasında $\left(X^{2}=3,720 ; p=0,042<0.05\right)$; duygusal ihmal yaşayanlar ve yaşamayanlar arasında $\left(X^{2}=4,899 ; \mathrm{p}=0,028<0.05\right)$ oranında anlamlı farklılık saptanmıştır. 
Güneri Yöyen, E. (2017). Çocukluk çağı travması ve benlik saygısı. International Journal of Social Sciences and Education Research, 3(1), 267-282.

$\mathrm{Bu}$ bulgu literatür ile desteklenmektedir. Ulusal alan yazınında 335 üniversite öğrencisi ile yapılan bir çalışmada duygusal ve fiziksel yönden ihmal edilen öğrencilerin benlik saygılarının istatistiksel olarak anlamlı şekilde daha düşük olduğu rapor edilmiştir (Onat, Dinç, Günaydın, Uğurlu, 2016:s. 9-15). Mullen, çocukluk döneminde istismar ve ihmalin uzun dönem etkilerini araştırdığı çalışmasında çocukluğunda travma yaşamış kadın katılımcılar ile çalışmış ve bu kadınların çocukluk dönemi istismar yaşantıları ile psikolojik sıkıntıları, düşük benlik saygısı ve kişilerarası problemler arasında yüksek bir ilişkinin varlığını rapor etmiştir (Mullen ve ark., 1996: s. 7-2). Çocukluk dönemi istismar ve ihmal yaşantılarının, çocuğun sağlıklı gelişimini engellediği ve benlik kapasitelerinde yetersizliklere yol açtığı; çocukların ihtiyaçlarının karşılanmamasının, çocuğun duygusal gelişimini etkilediği ve kendisinin iyi bir bakımı hak edip etmediğiyle ilgili düşüncelerini biçimlendirdiği; çocuğun ihtiyaçlarından dolayı utanç duymaya başladığı ve kendiyle ilgili hoşnutsuzluk duyguları geliştirdiği, böylece kendini değersiz hissederek olumsuz bir benlik saygısına sahip olduğu bilgisi yer almaktadır (Şirin, 2009:s.14-18).

Ulusal ve uluslararası alan yazınında cinsel istismarın benlik saygısının düşük oluşunda önemli bir faktör olduğu bilgisi yer almaktadır. Tebbutt ve arkadaşları tarafından yapılan cinsel istismara uğramış çocukların 5 yıl sonra değerlendirildikleri bir çalışmada çocukların \%43'ünün düşük benlik saygısına sahip oldukları bulunmuş olup yaşça büyük çocukların benlik saygılarının daha düşük olduğu ve aile fonksiyonundaki bozukluğun benlik saygısını ileri derecede etkilediği de saptanmıştır. Romans ve arkadaşlarının çalışmasında özellikle penetrasyonu içeren çocukluk çağı cinsel istismarı ile yetişkin çağdaki olumsuz benlik saygısı arasındaki ilişki net bir şekilde gösterilmiştir (Aktepe, 2009: s. 95-119). Uluslararası alan yazı incelendiğinde; Joslyn, cinsel istismara maruz kalmış olan ve olmayan 11-18 yaş ergenlerde istismarın benlik saygısı üzerinde etkisini araştırdığı çalışmasında, cinsel istismara maruz kalmış ergenlerin kalmayanlara göre benlik saygılarının daha düşük olduğunu ve hatta psikolojik stres faktörlerinin de düşük benlik saygısına ek olarak daha belirgin olarak yüksek olduğunu belirtmiştir. (Joslyn ve Shivakumara, 2013: s. 438).Tyler'ın 41 makale üzerinden yaptı̆̆ 1 üst-analiz çalışmasında da cinsel istismara maruz kalmanın bireylerde diğer psikiyatrik hastalık ve sorunların yanı sıra düşük benlik saygısına yol açtığı belirtilmiştir (Tyler, K., 2002: s. 567-589). Cinsel istismara uğrayanlarda, düşük benlik saygısına sahip olmanın yanı sıra depresyon veya aile fertlerinden/ arkadaşlarından uzaklaşma, tekrarlayan atipik ağrı, kendine zarar verici davranışlar, aşağılık duygusu gelişme riskinin de arttığı belirtilmektedir (Ovayolu, Uçan ve Serindağ, 2007:s.4). Araştırmada çocukluk çağı cinsel istismar yaşantısı olan katılımcılar ile olmayan katılımcılar karşılaştırılmış ve istatistiksel olarak anlamlı fark oluşmadığ 1 görülmüştür $\left(X^{2}=0,177 ; p=0,401>0.05\right)$. Bu sonucun örneklemden nicel özelliklerinden kaynaklanmış olabileceği öngörülmektedir. Örneklem incelendiğinde cinsel istismara maruz kalan öğrenci sayısı 96 kişidir ve bu gruptaki bireylerin benlik saygısı orta düzey için \%9,4 (9 kişi),yüksek düzey için \%90,6 ( 87 kişi) olarak belirlenmiştir; cinsel istismar yaşantısı olmayan katılımcı sayısı 434 kişidir ve bu kişilerin benlik saygısı orta düzeyde olanların oranı \%8,1 (35 kişi), yüksek olanların \%91,9 (399 kişi) olarak belirlenmiştir. Bu sayıların dağılımının istatistiksel farklılık oluşmamasında etken olduğu düşünülmektedir.

\section{Sonuç}

Çalı̧̧mada elde edilen sonuçlar üç başlık halinde toplanabilir. Bunlardan ilki erkeklerin çocukluk çağı travma toplam puanlarının, kadınların çocukluk çağ yükssek olduğu; çocukluk çağı travma alt boyutlarından fiziksel ihmalin ve cinsel istismarın erkeklerde, kızlara göre daha fazla görüldügüdür. Ülkemizin sosyal ve kültürel değerleri sadece 
çocukların çocukluk çağı travmalarının oranları ve çocukluk istismar ve ihmali yaşantısının cinsiyet üzerindeki dağılımın açığa çıkarmakta bir engel teşkil etmekle kalmamakatadır aynı zamanda özellikle cinsel istismar ve ihmal yaşantısına karşı kız çocuklarında daha fazla koruyucu önlemler almaya itmektedir. Ancak ülkemizde erkek çocuklarının yaşadıkları çocukluk çağı istismar ve ihmal yaşantısı kız çocuklarından az değildir ve hatta daha yüksektir. Bunda toplumumuzun kız ve erkek çocuklarının cinsiyet rolüne yüklediği değerlerin önemli olduğu düşünülmektedir.

Çalışmada elde edilen sonuçların ikincisi bireylerde çocukluk çağı travmasının mevcut olmasının benlik saygısını düşürdügü̈; ancak benlik saygısı düzeyinin belirleyicisi olarak çocukluk çağ1 travmalarının açıklayıcılık gücünün zayıf olduğudur. Üçüncüsü bulgu ise bu zayıf ilişkiye rağmen çocukluk çağı travması alt boyutlarının tamamının (duygusal istismar, fiziksel istismar, fiziksel ihmal, duygusal ihmal ve cinsel istismar) benlik saygısının düşük olmasında önemli olduğudur. Bireyin kendisini ilişkin olumlu görüşleri, kendisini değerli ve yeterli görmesi, yetenekleri ve becerilerini olumlu olarak algılaması bireyin benlik saygısının yüksek olduğunu gösterir ve öğrenilmiş bir yaşantı olarak yaşam boyu devam eder. Yaşamın ilk yıllarında aile ile olan ilişkiler ile başlayan daha sonra bireyin sosyal çevresi tarafından katkı sunulan benlik saygısı bireylerin yaşam boyu akademik ve yaşamsal başarılarında önemli bir yere sahiptir ve bireylerin psikolojik ve sosyal yaşantılarında, akademik başarılarında ve problemleri çözebilmelerinde önemli bir olgudur. Bireye yönelik en ağır şiddet ve suç olarak kabul edilen çocuk istismarı ve ihmali ile bireyin çocukluk döneminde karşılaştığı çocukluk çağı travmaları, bireylerin benlik saygısını önemli ölçüde etiklemektedir ve bir çok ruhsal rahatsızlığın kaynağını oluşturmaktadır. $\mathrm{Bu}$ bağlamda ailenin işlevi sadece çocuğunun bakımı, eğitimi, psikolojik ve sosyal gelişimini desteklemek değil aynı zamanda çocuğunu istismar ve ihmal yaşantısına karşı korumaktır. Bu sadece ailenin değil tüm toplumun ve yasaların sorumluluğu ve ortaya çıkardığı etkileri ile yine sadece ailenin değil aynı zamanda tüm toplumun sorunudur.

\section{7. Öneriler}

Ülkemizde çocukluk çağı travmasının, çocuk istismarı ve ihmalinin yaygın bir halk sağlığı sorunu olduğu bilinmektedir. Ancak özellikle cinsel istismar başta olmak üzere diğer travma tiplerinin de aile bütünlüğünü korumak, sosyal dışlanmayı önlemek sebebiyle bildiriminin yapılmadığg da bilinmektedir. Kişinin kim olduğu, kendisini algılayış biçimi ve kendisine dair olan düşüncelerinin ifadesi olan benlik saygısı ise bireyin yaşamı boyunca iyi oluşu için sahip olması gereken önemli bir fenomendir. Çocukluk çağı travmasını benlik saygısı üzerindeki etkisine ilişkin ülkemizde çalışmaların az sayıda olduğu dikkat çekmektedir. Çalışmalar daha ziyade klinik popülasyondan elde edilmiştir. Bu bağlamda ülkemizde sağlıklı bireyler üzerinden yürütülecek çalışmalara ihtiyaç vardır. Bu çalışmaların niteliksel ve niceliksel artışının; çocukluk çağı travmaları, istimar ve ihmal yaşantıları ile bireylerin benlik saygısı arasındaki ilişkilerin açığa çıkartılmasında, gerek çocukluk çağı travmalarının azalmasında ve gerekse benlik saygısının yükseltilmesi için eğitsel, sosyal, hukuksal ve psikolojik önlemlerin alınmasında ailelere, eğitim kurumlarına, yasa koyuculara, psikiyatrist, psikolog, psikolojik danışman ve diğer ruh sağlığı çalışanları ile sosyal çalışma uzmanlarına 1şık tutacağı düşünülmektedir.

\section{Kaynakça}

Akbaş, G.E. (2014). Farklı sosyoekonomik düzeydeki ergenlerin çocukluk dönemi istismar yaşantıları: Ankara Altındağ ve Çankaya örneği. Toplum ve Sosyal Hizmet, 25 (2), 75-96. 
Güneri Yöyen, E. (2017). Çocukluk çağı travması ve benlik saygısı. International Journal of Social Sciences and Education Research, 3(1), 267-282.

Aktepe, E. (2009). Çocukluk çağı cinsel istismarı. Psikiyatride Güncel Yaklașımlar-Current Approaches In Psychiatry, (1), 95-119.

Algül, A., Ateş, A. M., Gülsün, M., Darık, A., Semiz, Ü.B., Başoğlu, C., Ebrinç, S. \& Çetin, M. (2009). Antisosyal kişilik bozukluğu olgularında kendini yaralama davranışının saldırganlık, çocukluk çağı travmaları ve dissosiyasyon ile ilişkisi. Anatolian Journal of Psychiatry, (10), 278-285.

Aslan, S.H. \& Alparslan, Z.N. (1999). Çocukluk örselenme yaşantıları ölçeğinin bir üniversite öğencisi örnekleminde geçerlik, güvenirlik ve faktör yapısı. Türk Psikiyatri Dergisi, 10(2), 275-85.

Balat, G.U. \& Akman, B. (2004). Farklı sosyo-ekonomik düzeydeki lise öğrencilerinin benlik saygısı düzeylerinin incelenmesi. Furat Üniversitesi Sosyal Bilimler Dergisi, (14, 2), 175-183.

Demirkapı, E.Ş. (2013). Çocukluk Çağı Travmalarının Duygu Düzenleme ve Kimlik Gelişimine Etkisi ve Bunların Psikopatolojiler İle İlişkisi. Yayınlanmamış Yüksek Lisans Tezi: Adnan Menderes Üniversitesi, Aydin.

Ekinci, S. (2010). Fiziksel çocuk istismar1, Katkı Pediatri Dergisi, 32 (5), 625- 631.

Eroğlu, A.R.Ç. \& Türk, S.B. (2013). Ergenlerde çocukluk örselenme yaşantıları ve öfke ifade tarzları ile benlik saygısı ve yaşam doyumu arasındaki ilişkilerin incelenmesi. Journal of Human Sciences, 10 (1). 1422-1439.

Etain, B., Mathieu, F., Henry, C., Raust, A., Roy, I., Germain, A. \& Bellivier, F. (2010). Preferential association between childhood psychological maltreatment and bipolar disorder. Journal of Traumatic Stress, 23(3), 376-383.

Evren, C. \& Ögel, K. (2003). Alkol/madde bağımlılarında dissosiyatif belirtiler ve çocukluk çağı travması, depresyon, anksiyete ve alkol/ madde kullanımı ilişkisi. Anadolu Psikiyatri Dergisi, (4), 30-37.

Glaser, D. (2002). Emotional abuse and neglect (psychological maltreatment): A conceptual framework. Child Abuse Negl, (26), 697-714.

Güleç, H., Topaloğlu, M., Ünsal, D. \& Altıntaş, M. (2012). Bir kısırdöngü olarak şiddet. Psikiyatride Güncel Yaklaşımlar-Current Approaches in Psychiatry, 4(1), 112-137.

Güler, N., Uzun, S., Boztaş, Z. \& Aydoğan, S. (2002). Anneleri tarafından çocuklara uygulanan duygusal ve fiziksel istismar/ihmal davranışı ve bunu etkileyen faktörler. Cumhuriyet Üniversitesi Tıp Fakültesi Dergisi, 24 (3), 128-134.

Joslyn, H. \& Shivakumara K.( 2013). Self-esteem and psychological distress among sexually abused and sexually non-abused adolescents. International Journal of Science and Research, 6 (14), 438.

Kalkan, M. \& Özbek, S.K. (2011). Çocukluk çağı örselenme yaşantıları ergenlerdeki flört kaygısını yordar mi?. Turk J Child Adolesc Ment Health, 18(1), 35-44.

Mullen, P., Martin, J., Anderson, J., Romans, S. \& Herbison, G. (1996). The long-term impact of the physical, emotional, and sexual abuse of children: A community study. Child Abuse \& Neglect, (20), 7-2.

Onat, G., Dinç, H., Günaydın, S. \& Uğurlu, F. (2016). Çocukluk döneminde yaşanan ihmal veya istismarın benlik saygısına etkisinin incelenmesi. 3(1), 9-15. DOI:10.17681/hsp.61140 HSP [Elde edilme tarihi: 04.05.2016, http://dergipark.ulakbim.gov.tr/iuhsp/article/viewFile/5000131558/5000156038]

Ovayolu, N., Uçan, Ö. \& Serindağ, S. (2007). Çocuklarda cinsel istismar ve etkileri. Fırat Să̆lık Hizmetleri Dergisi, 2, 4.

Örsel, S., Karadağ, H., Kahiloğulları, A., Karaoğlan, A. \& Akgün, E. (2011). Psikiyatri hastalarında çocukluk çağı travmalarının sıklığı ve psikopatoloji ile ilişkisi. Anatolian Journal of Psychiatry / Anadolu Psikiyatri Dergisi, 12 (2), 130-136.

Özen, Ş., Antar, S. \& Özkan, M. (2004). Çocukluk çağı travmalarının umutsuzluk ve depresif duygu durum üzerine etkisinin son sınıf üniversite öğrencilerinde incelenmesi. 40. Ulusal Psikiyatri Kongresi, Türk Psikiyatri Derneği Yayınları, 316-9. 
Güneri Yöyen, E. (2017). Childhood trauma and self-respect. International Journal of Social Sciences and Education Research, 3(1), 267-282.

Özmert, E.N. (2006). Erken çocukluk gelişiminin desteklenmesi-iii: aile. Çocuk Sağlığl ve Hastalıkları Dergisi, (49). 256-273.

Pelcovitz, D., Kaplan, S., Goldberg, B., Mandel, F., Lehane, J. \& Guarrera, J. (1994). Posttraumatic stress disorder in physically abused adolescents. J Am Acad Child Adolesc Psychiatry, 33, 305-312.

Peled, E. (1998). The experience of living with violence for preadolescent witnesses of woman abuse. Youth Soc, (29), 395-430.

Richards, F. \& O'Keeffe, Z. C. (2004). Resilience and risk factors associated with experiencing childhood sexual abuse. Child Abuse Review, 13(5), 338-352.

Şenkal, İ. \& Işıklı, S. (2015). Çocukluk çağı travmalarının ve bağlanma biçiminin depresyon belirtileri ile ilişkisi: Aleksitiminin aracı rolü. Türk Psikiyatri Dergisi, 26 (4):261-67.

Şenkal, İ. (2013). Üniversite Öğrencilerinde Çocukluk Çağı Travmaları ve Bağlanma Biçiminin Depresyon ve Kaygı Belirtileri İle İlişkisinde Aleksitiminin Aracı Rolünün İncelenmesi. Yüksek Lisans Tezi: Hacettepe Üniversitesi, Ankara.

Şirin, E. (2009). Üniversite Öğrencilerinde Kendine Zarar Verme Davranışının Demografik Değişkenler, Travmatik Yaşantılar ve Benlik Kapasitesi Ille Olan İlişkisi. Yayınlanmamış Yüksek Lisans Tezi: Dokuz Eylül Üniversitesi, İzmir.

Taner, Y. \& Gökler, B. (2004). Çocuk istismarı ve ihmali: Psikiyatrik yönleri. Haccettepe Tip Dergisi, 35, 82-86.

Trraşçı, İ.Y. \& Gören, S. (2007). Çocuk istismarı ve ihmali. Dicle Tip Dergisi, 34 (1), 70-74.

Tirali, R.E., Oğuz, Y. \&Soydan, S.S. (2014). Çocuk istismar ve ihmalinin oral bulguları. Atatürk Üniversitesi Diş Hekimliği Fakültesi Dergisi, 9, 154-157.

Turhan, E., Sangün, Ö. \& İnandı, T. (2006). Birinci basamakta çocuk istismarı ve önlenmesi. Sted, 15(9), 153. [Elde edilme tarihi: 12.05.2016, http://www.ttb.org.tr/STED/2006/eylul/birinci.pdf ]

Tyler, K. (2002). Social and emotional outcomes of childhood sexual abuse: a review of the recent research. Aggression and Violent Behaviour, 7(6), 567-89.

Zeren, C., Yengil, E., Çelikel, A., Arık, A. \&Arslan, M. (2012). Üniversite öğrencilerinde çocukluk çağı istismarı sıklı̆̆ı. Dicle Tip Dergisi, 39 (4), 536-541.

Zoroğlu, S. S., Tüzün, Ü., Şar, V., Öztürk, M., Kora, M. E. \& Alyanak, B. (2001). Çocukluk dönemi istismar ve ihmalinin olası sonuçları. Anadolu Psikiyatri Dergisi, 2(2):69-78.

\section{Extended abstract in English}

Introduction: The fact that children are exposed to pyhsical, emotional, mental or social abuse by their parents or those who look after them is called childhood trauma, in other words, childhood abuse and neglect (Demirkap1, 2013: pp.1-6). It is clear that childhood abuse and neglect may produce undesired results in an individual's process of growth (Richards \& O'Keeffe, 2004:pp. 338-352). It is known that childhood abuse and neglect is important in an individual's development of psychopathology (Etain at all., 2010: pp. 376-383); and that there is a remarkable factor which is related to disassociative symptoms physically and the act of hurting oneself physically and suicide (Zoroğlu at all., 2010:pp. 69-78), antisocial personality disorders (Algül at all., 2009: pp. 278-285), mood and anxiety disorders along with other psychiatric illnesses (Örsel at all., 2011:pp. 130-136), sleep disorders, nightmares, phobias, somatic compliance ,fear reaction, attention-deficit hyperactivity disorder, secondary enuresis, amnesia in the early period of abuse, too much fantasy, trance-like situations, sleepwalking, high level of depression, posttraumatic stress disorder, somatisation disorder, hipochondriasis, eating disorders, sexual dysfunction, borderline personality disorder, conversion disorder, developmental disorders, panic disorder, the 
Güneri Yöyen, E. (2017). Çocukluk çağı travması ve benlik saygısı. International Journal of Social Sciences and Education Research, 3(1), 267-282.

rise in delinquency and violence (Güleç, Topaloğlu, Ünsal, \& Altıntaş, 2012:pp.112-137). There are findings which report that chilhood trauma, abuse and neglect considerably affect psychiatric illnesses as well as self-respect (Pelcovitz at all., 1994:pp. 305-312; Özmert, 2006:pp. 256-273; Tıraşçı \& Gören, 2007:pp. 70-74; Eroğlu \& Türk, 2013: pp. 1422-1439; Peled, 1998:pp. 395-430; Onat, Dinç, Günaydın \& Uğurlu, 2016:pp.9-15; Joslyn \& Shivakumara, 2013:pp. 438; Tyler, 2002:pp. 567-89; Ovayolu, Uçan \& Serindağ, 2007:pp.4).

Purpose: This study aims to determine the correlation between childhood trauma and selfrespect, how trauma affects self-respect and to obtain the data of the rate of trauma and gender distribution. The research covers students at İstanbul Gelişim University, Faculty of Economics, Administrative and Social Sciences in the 2014-15 academic year. The sample of the research covers 530 participants in the 1st, 2nd, 3rd and 4th grades on a volunteer basis. The study is confined to the sample of the university in which it has been carried out and the data based on the declaration of the sample.

Method: In this study, descriptive survey model has been used. The data have been obtained by use of "Rosenberg Self-respect Scale" and "Childhood Trauma Scale". The t-test has been used to determine if the total point average of childhood trauma is remarkably different from gender distribution; correlation analysis has been applied to determine the relation between the total point of childhood trauma and self-respect; regression analysis has been applied to determine the relation between childhood trauma and self-respect; the chi square test has been used to compare those with childhood trauma to those with no childhood trauma in terms of self-rescpect; frequency and arithmetic average have been used for distribution and definitive findings. The statistical analysis of the data produced from the research has been made bye use of IBM SPSS 22.0 and significance level has been determined as $[\mathrm{p} \leq .05]$

Findings: Study participants are made up of 303 girls $(\% 57,2)$ and 227 boys( $\% 42,8)$. In 165 of students $(\% 31,1)$ childhood trauma has been observed. The distribution of sub-dimensions of trauma is as follows: emotional abuse \% 26,4 ( 140 ); physical abuse \% 12,5 (66); physical neglect $\%$ 30,4( 161); emotional neglect \%15,7 ( 83); sexual abuse \% 18,1(96).

The total point of childhood trauma of the participants is significant $(t=-3,144 ; \mathrm{p}=0,002<0,05)$ when it comes to gender variable. Male students' total point of childhood trauma $(X=36,300)$, physical neglect point $(\mathrm{t}=-4,083 ; \mathrm{p}=0,000<0,05)$, sexual abuse point $(\mathrm{t}=-3,392 ; \mathrm{p}=0,001<0,05)$ are significantly different from those of female students.

A positively significant relation which is $\% 23,9$ between total point of chilhhood trauma and self-respect has been determined $(r=0,239 ; p=0,000<0,05)$.

Regression analysis made to determine the relation between childhood trauma and self-respect is significant $(\mathrm{F}=11,470 ; \mathrm{p}=0,000<0.05)$. But as a determiner of self-respect level childhood trauma is a weak factor to give reasons $(\mathrm{R} 2=0,090)$. Emotional abuse $(\beta=0,054)$ and physical abuse $(\beta=0,059)$ decrease self-respect.

In terms of self-respect there is a significant difference between those with childhood trauma and those with no childhood trauma $\left(X^{2}=14,766 ; p=0,000<0.05\right)$ between those with emotional abuse and those with no emotional abuse $\left(X^{2}=6,940 ; p=0,009<0.05\right)$ between those with physical abuse and those with no physical abuse $\left(X^{2}=9,667 ; p=0,004<0.05\right)$, between those with physical neglect and those with no physical neglect $\left(X^{2}=3,720 ; p=0,042<0.05\right)$, between those with emotional neglect and those with no emotional neglect $\left(X^{2}=4,899 ; p=0,028<0.05\right)$. On the other hand 
there is no significant difference between those with sexual abuse and with no sexual abuse $\left(\mathrm{X}^{2}=0,177 ; \mathrm{p}=0,401>0.05\right)$.

Discussion: In the research, in \% 31,1 of the participants childhood trauma has been determined ; in \% 26,4 of them emotional abuse has been determined; in \% 12,5 of them physical abuse has been determined; in \% 30,4 of them physical neglect has been determined; in \% 15,7 of them emotional neglect has been determined; in \% 18,1 of them sexual abuse has been determined. All those findings are in accordance with the ones which have been determined before. What has already been observed in this area reports that the rate of child abuse in the world is $\% 52$ for girls and \% 48 for boys and that the rate of child abuse is \% 33 in Turkey (Tirali, Oğuz \& Soydan, 2014: pp. 154-157). In this research the rate of childhood trauma has been determined as \% 31,1 and what we have obtainted is largely in accordance with that of Tirali's. In the study it is clear that as a childhood trauma, emotional abuse is followed by physical abuse, physical neglect, emotional neglect and sexual abuse. All these findings are in accordance with the ones which have been observed before. In child abuse surveys in Turkey emotional abuse is $\% 78$ in the lead. This is followed by physical abuse and sexual abuse (Turhan, Sangün \& İnand1, 2006: pp.153).

In the survey male students' chilhood trauma is higher than that of female students. As for the sub-dimensions of childhood abuse physical neglect point and sexual abuse point are significant for male students. In the survey the fact that physical neglect and sexual abuse for boys are higher than for girls is in accordance with the one which has been observed before. When the national data are examined, in the researches done by use of childhood disturbance scale, which puts childhood trauma into 3 groups: emotional abuse and neglect, physical abuse and neglect and sexual abuse, neglect and abuse are reported to be higher for boys than for girls (Zeren at all., 2012:pp. 536-541; Aslan \& Alparslan, 1999:pp. 275-85; Özen, Antar \& Özkan 2004:pp.316-9). In a study of 450 teenagers made by Eroğlu and Türk it is reported that sexual abuse for boys is higher than for girls (Eroğlu \&Türk, 2013:pp. 1422-1439)

In the research it has been found out that childhood trauma decreases self-respect and that as childhood trauma point decreases self- respect. The finding is in accordance with what has already been observed .It is reported that childhood abuse and neglect is a factor to develop low selfrespect (Özmert, 2006: pp. 256-273; Tıraşç1 \& Gören, 2007:pp. 70-74). In a recent nationwide study the relation between self- respect and satisfaction and disturbed childhood and ways of expressing anger in teenagers have been examined and it is reported that teenagers with physical ,emotional and sexual abuse have lower self-respect than those with no physical, emotional and sexual abuse (Eroğlu \&Türk, 2013:pp. 1422-1439; Peled, 1998:pp. 395-430).

The last finding of the research has been obtained comparing the self-respect of the students with childhood trauma with the one of those with no childhood trauma and it has been observed that in terms of self respect there is a significant difference between those with childhood trauma and those with no childhood trauma. As the sub-dimensions of childhood trauma, emotional abuse, physical abuse, physical neglect, emotional neglect and sexual abuse decrease self-respect when it comes to students who haven't gone through any of them. This finding is supported by what has been determined before. The fact that childhood trauma is an important factor, which decreases self-respect level, is reported in several studies (Şirin, 2009:pp.14-16; Aktepe, 2009:pp. 95-119; Joslyn \& Shivakumara, 2013:pp.438; Tyler, 2002:pp. 567-89; Ovayolu, Uçan \& Serindağ, 2007:pp.4) . In a national study of 335 university students it is reported that self-respect 
Güneri Yöyen, E. (2017). Çocukluk çağı travması ve benlik saygısı. International Journal of Social Sciences and Education Research, 3(1), 267-282.

of the students with emotional and physical neglect is significantly low in terms of statistics (Onat, Dinç, Günaydın \& Uğurlu, 2016:pp.9-15). In this study in which he searched for the long-term effect of childhood abuse and neglect, Mullen worked with female participants with childhood abuse and reported that there was a remarkable relationship between interpersonal problems and low self- respect and the women's childhood abuse and psychological problems (Mullen, Martin, Anderson, Romans \& Herbison, 1996:pp.7-2).

Result: In the study the male students' total childhood trauma point, physical neglect and sexual abuse are higher than those of female students. Our national social and cultural values not only prevent childhood trauma rate and distribution of childhood abuse and neglect on gender from being revealed but also push girls to take more precautions against childhood trauma such as sexual abuse and neglect. In our country boys' childhood abuse and neglect are not lower than those of girls. That is because our society attaches more importance to boys than to girls.

In the study it has been determined that individuals childhood trauma decreases self-respect, but as a determiner of self-respect level childhood trauma is a weak factor to give reasons. Despite this weak relationship all the sub-dimensions of childhood trauma (emotional abuse, physical abuse, physical neglect, emotional neglect and sexual abuse) are considerably significant factors to reduce self-respect. The fact that the individual has a high opinion of himself / herself, that he/ she thinks he/ she is valuable, and that he/she perceives his/ her talents are positive shows that the individual's self-respect is high and this lasts till the end of time. Self-respect, which begins with the relation with the family in the early year of life and to which the individual's social circle contributes, plays an important role on the vital and academic achievements and is a considerable fact for the psychological and social life as well as for problem solving. Child abuse and neglect accepted as the most offensive violence and crime together with childhood trauma affect selfrespect a great deal and are the source of a number of psychological disorders. In this context, the family should not only support child's care, education, psychological and social development but also should protect child against abuse and neglect.

The whole society and laws are responsible for this as well as the family and the problem is not only of the family but also of the entire society in terms of the results it produces

Suggestions: In our country childhood trauma, child abuse and neglect are known to be common public health problems. On the other hand, the other types of trauma, especially sexual abuse, are known not to be reported in order to keep family unity and to prevent social isolation. Selfrespect, which is an expression of one's opinion of oneself, a way of telling who one is and what one feels about oneself, is an important phenomenon that one needs to have with a view to being well for a lifetime. It is remarkable that there are a small number of studies on childhood trauma and self-respect in our country. Studies have been made by use of clinical population on a large scale. In this sense, studies which will be able to be carried out by employing healthy people are needed in Turkey. The fact that a lot more studies of this kind are made in terms of quality and quantity are supposed to clarify the relationships between childhood trauma, abuse neglect and self-respect and to help families, academic institutions, law makers, psychiatrists, psychologists, psychological counselors and social care specialists to take educational, social legal and psychological measures in order to reduce childhood trauma and increase self-respect. 